\title{
COVID-19 mortality among pregnant women in Mexico: A retrospective cohort study
}

\author{
Mónica Ríos-Silva ${ }^{1,2}$, Efrén \\ Murillo-Zamora ${ }^{3}$, Oliver \\ Mendoza-Cano ${ }^{4}$, Xóchitl Trujillo', \\ Miguel Huerta ${ }^{1}$ \\ ${ }^{1}$ Centro Universitario de Investigaciones \\ Biomédicas, Universidad de Colima, \\ Colima, Mexico \\ ${ }^{2}$ Cátedras CONACyT, Universidad \\ de Colima - Centro Universitario de \\ Investigaciones Biomédicas, Colima, \\ México \\ ${ }^{3}$ Departamento de Epidemiología, Unidad \\ de Medicina Familiar No. 19, Instituto \\ Mexicano del Seguro Social, Colima, \\ Colima, México \\ ${ }^{4}$ Facultad de Ingeniería Civil, Universidad \\ de Colima, Coquimatlán, Colima, México
}

\begin{abstract}
Background Pregnant women have been classified as at risk for COVID-19 due to previous experience with influenza and other coronaviruses. The objective of this study was to identify risk factors for the complications and death in women of childbearing age and pregnant women with suspected COVID-19.
\end{abstract}

Methods This retrospective cohort study was conducted from the beginning of the epidemic in Mexico until May 25, 2020. All women of childbearing age (13-49 years) from the open national COVID-19 database from the Ministry of Health of Mexico were considered for eligibility. SARS-COV-2 infection was confirmed or ruled out by RT-qPCR. We performed a bivariate and multivariable analysis to estimate mortality risk.

Results Ten (2.2\%) pregnant women with confirmed COVID-19 died. Positive pregnant patients did not have a higher risk of complications (admission to the ICU, pneumonia, or requirement for mechanical ventilation) or death than the controls. In the multivariate analysis, only history of diabetes and chronic kidney disease remained independently associated with death in the positive cohort. Seven $(0.6 \%)$ pregnant women with a negative test died. In bivariate analysis, pregnant patients with a positive test had a higher risk of death than pregnant patients with a negative test (relative risk $(R R)=3.87,95 \%$ confidence interval $(C I)=1.48-10.12$ ), but no higher risk was found than in non-pregnant women with a positive test $(\mathrm{RR}=0.82,95 \% \mathrm{CI}=0.44-1.53)$, and 60-day mortality did not significantly differ among pregnant patients with or without a positive test (hazard ratio $(\mathrm{HR})=0.40,95 \% \mathrm{CI}=0.12-1.30)$ or between COVID-19-positive patients who were pregnant or not pregnant $(\mathrm{HR}=0.74,95 \% \mathrm{CI}=0.35$ 1.56).

Conclusions Pregnant patients do not have a greater risk of complications or death from COVID-19 than non-pregnant patients. The presence of diabetes mellitus and chronic disease increases the risk of death in women of childbearing age, but not specifically in pregnant patients.

The COVID-19 pandemic caused by SARS-CoV-2 has generated worldwide alarm and mobilized all health services. Sectors of the population that are particularly vulnerable to serious disease and increased mortality have been identified, including patients with chronic degenerative diseases [1]. In addition, pregnant patients have been classified as high risk due to previous experience 
in pandemic influenza [2] and other diseases caused by other coronaviruses [3], but epidemiological studies have not conclusively demonstrated increased mortality in pregnant women compared to non-pregnant women [4]. To date, no specific authorized treatment is available for COVID-19, and some promising drugs do not have enough information regarding their safety during pregnancy. Furthermore, some therapeutic supportive measures, such as the prone position, are not possible in the last trimesters of pregnancy [5,6].

In Mexico, the general maternal morbidity and mortality has been estimated as a Maternal Mortality Ratio (MMR) of 34.5 deaths for every 100000 estimated births [7]. Risk factors, such as teenage pregnancies, diabetes, obesity, and hypertension, have a higher prevalence [8,9]. Mexican health authorities have reported less use of health reproductive services by women of childbearing age, suggesting that the presence of SARS-CoV-2 infection could increase maternal morbidity and mortality rates. This increase in maternal mortality due to indirect factors of the use and availability of health services is estimated to range from 8.3 to $38.6 \%$ per month in low and middle income countries[10]. Given that COVID-19 is an emerging disease, information on its epidemiology in pregnant women is limited. Thus, the objective of the present study was to identify risk factors for the presence of complications and death in women of childbearing age and pregnant women with suspected COVID-19.

\section{METHODS}

\section{Study design and participants}

This retrospective cohort study included women of childbearing age (13 to 49 years)[11] from the open national database of COVID-19 [12] from the Ministry of Health of Mexico. All women of childbearing age included from the beginning of the epidemic in Mexico until May 25, 2020, were considered for eligibility.

\section{Procedures}

Data were extracted from the open database, which includes anonymous information on cases studied by the General Directorate of Epidemiology of the Ministry of Health for epidemiological surveillance purposes; it includes suspected cases, negative cases, and confirmed cases. Suspicious cases were cataloged according to the operational definition issued by the Ministry of Health of Mexico, which includes the presence in the last 7 days of at least two of three symptoms, cough, fever, or headache, in addition to at least one of the following symptoms: dyspnea, arthralgia, myalgia, sore throat, runny nose, conjunctivitis, or chest pain. SARS-CoV-2 infection was confirmed or ruled out by laboratory tests utilizing quantitative reverse transcription polymerase chain reaction (RT-qPCR). The epidemiological surveillance network established that the tests would be carried out in 10\% of the suspected cases cataloged as mild and $100 \%$ of severe cases (ie, anyone who meets the definition of a suspected case and also has difficulty breathing and is hospitalized). The database includes all cases in which a blood test was performed. The variables included in this database were sex; age; whether the patient received outpatient care or required hospitalization; presence of pregnancy; smoking history; date of onset of symptoms, admission to hospital, and death if applicable; history of diabetes mellitus (DM), chronic obstructive pulmonary disease (COPD), asthma, immunosuppression, hypertension, cardiovascular disease, obesity, chronic kidney disease, or diagnosis of other unspecified comorbidity; presence of complications, such as diagnosis of pneumonia, mechanical ventilation required, and intensive care in intensive care unit (ICU). The database also reports demographic variables corresponding to the geographic distribution of the cases. Women with missing clinical or epidemiological data were excluded. The database is available under an international license, CC-BY-ND 4.0.

The main outcome was to establish whether pregnant women with laboratory-confirmed COVID-19 have a higher risk of mortality vs non-pregnant women of childbearing age with laboratory-confirmed COVID-19 and pregnant women with suspected COVID-19 but with a negative test. The secondary outcomes were to establish whether the presence of chronic degenerative diseases increases the mortality rate in pregnant women with laboratory-confirmed COVID-19.

\section{Statistical analysis}

We performed a descriptive analysis of the data; the continuous variables were expressed as medians and interquartile ranges (IQRs) and the categorical variables as frequencies and proportions (\%). First, statistical analyses were performed in pregnant women with SARS-COV-2 positive tests using non-pregnant wom- 
en of childbearing age as the control group. Next, statistical analyses were performed in pregnant women with suspected COVID-19 using pregnant women with a negative SARS-COV-2 test as the control group. In the bivariate analysis, a $\chi^{2}$ test was used to establish the association between the presence of pregnancy or a positive test and the presence of comorbidities reported in the database (DM, COPD, asthma, immunosuppression, hypertension, obesity, cardiovascular disease, chronic kidney disease, smoking, and other comorbidity), as well as the association of pregnancy with the presence of complications (pneumonia, admission to ICU, need for mechanical ventilation, and/or death), the association between the presence of comorbidities and the type of care required by the patient (outpatient vs hospitalization), and the association of comorbidities and death. We estimated the relative risk (RR) with 95\% confidence intervals (CIs). For the quantitative variables, the data distribution was estimated using the Kolmogorov-Smirnov test. For a non-parametric distribution we used the Mann-Whitney U test. For the multivariate analysis, Cox proportional risk models for the risk of 60-day COVD-19 mortality in women of childbearing age considering the time from the onset of symptoms included all comorbidities adjusted for age and pregnancy status. Cox proportional risk models were also used to establish the risk of a positive test in pregnant women considering the time form the onset of symptoms until health service contact. We also estimated average hazard ratios using Mantel-Haenszel estimators. All statistical tests were two-tailed, and significance was set at $\alpha=0.05$. Statistical analysis was performed with SPSS version 20.0 (IBM corporation,Armonk NY, USA), for the realization of the graphs was used GraphPad Prism 6.01 (GraphPad Software, San Diego CA, USA).

\section{RESULTS}

Between February 28, 2020 (the first confirmed case in Mexico) and May 25, 2020, a total of 225650 suspected cases of COVID-19 were identified, $48 \%$ corresponding to women. The median age of women with a positive test was 36 years (IQR $=29-43)$, and $448(2.49 \%)$ of these women were pregnant (Figure 1). The cohort included 19636 women; 1486 (7.5\%) had DM, 83 (0.4\%) COPD, 853 (4.3\%) asthma, 259 (1.32\%) immunosuppression, 1710 (8.3\%) hypertension, 3724 (18.9\%) obesity, 209 (1.06\%) cardiovascular disease, 209 (1.06\%) chronic kidney disease, 1093 (5.5\%) smoking, and 773 (3.9\%) other not specified comorbidity.

\section{Women with positive SARS-COV-2 test}

The median age of pregnant women was significantly lower than that of non-pregnant controls. The most frequent chronic condition in both pregnant and non-pregnant women was obesity, but pregnant patients had a higher risk of having another not specified comorbidity ( $R R=1.98,95 \% \mathrm{CI}=1.39-2.81$; Table 1$)$.

In the bivariate analysis, hospitalized patients were older than those who received outpatient treatment (41 years, IQR $=33-46$ vs 36 years, IQR $=29-42 ; P<0.001$ ). This was also seen with the control group, in which the significant difference in age was maintained between those who received outpatient treatment (36 years, $\mathrm{IQR}=30-42$ ) and those who were hospitalized (41 years, IQR=34-46; $P<0.001$ ).

Table 1. Clinical characteristics of women of childbearing age with COVID-19

\begin{tabular}{|c|c|c|c|c|c|}
\hline & $\begin{array}{l}\text { No. PREENANT POSITIVE TESTS }(\%) \\
\qquad(\mathrm{N}=448)\end{array}$ & $\begin{array}{l}\text { No. not Pregnant POSITIVE TESTS (\%) } \\
\qquad(\mathrm{N}=17 \mathrm{942})\end{array}$ & P value ${ }^{*}$ & $\begin{array}{l}\text { No. PregnaNt Negative } \\
\text { TESTS }(\%)(N=1216)\end{array}$ & P valuet \\
\hline Age (median, IQR) & $29(25-33)$ & $37(30-43)$ & $<0.001$ & $28(23-32)$ & $<0.001$ \\
\hline $\mathrm{DM}$ & $17(3.7 \%)$ & $1440(8.2 \%)$ & 0.001 & $29(2.4 \%)$ & 0.1 \\
\hline COPD & $1(0.2 \%)$ & $79(0.4 \%)$ & 0.4 & $3(0.2 \%)$ & 0.4 \\
\hline Asthma & $11(2.4 \%)$ & $783(4.3 \%)$ & 0.04 & $59(4.9 \%)$ & 0.03 \\
\hline Immunosuppression & $7(1.5 \%)$ & $228(1.2 \%)$ & 0.5 & $24(2.0 \%)$ & 0.5 \\
\hline Hypertension & $17(3.7 \%)$ & $1655(9.2 \%)$ & $<0.001$ & $38(3.1 \%)$ & 0.5 \\
\hline Obesity & $59(13.1 \%)$ & $3563(19.9 \%)$ & $<0.001$ & $102(8.4 \%)$ & 0.003 \\
\hline Cardiovascular disease & $2(0.4 \%)$ & $199(1.1 \%)$ & 0.1 & $8(0.7 \%)$ & 0.6 \\
\hline Chronic kidney disease & $2(0.4 \%)$ & $202(1.1 \%)$ & 0.1 & $5(0.4 \%)$ & 0.9 \\
\hline Smoking & $12(2.6 \%)$ & $1043(5.8 \%)$ & 0.005 & $38(3.1 \%)$ & 0.6 \\
\hline Another comorbidity & $32(7.1 \%)$ & $655(3.6 \%)$ & $<0.001$ & $86(7.1 \%)$ & $<0.001$ \\
\hline
\end{tabular}

$\mathrm{DM}$ - diabetes mellitus, COPD - chronic obstructive pulmonary disease, IQR - interquartile range

*Mann-Whitney U test for continuous variables, $\chi^{2}$ test for categorical variables comparing pregnant with positive test vs not pregnant with positive test.

$†$ Mann-Whitney U test for continuous variables, $\chi 2$ test for categorical variables comparing pregnant with positive test vs pregnant with negative test. 


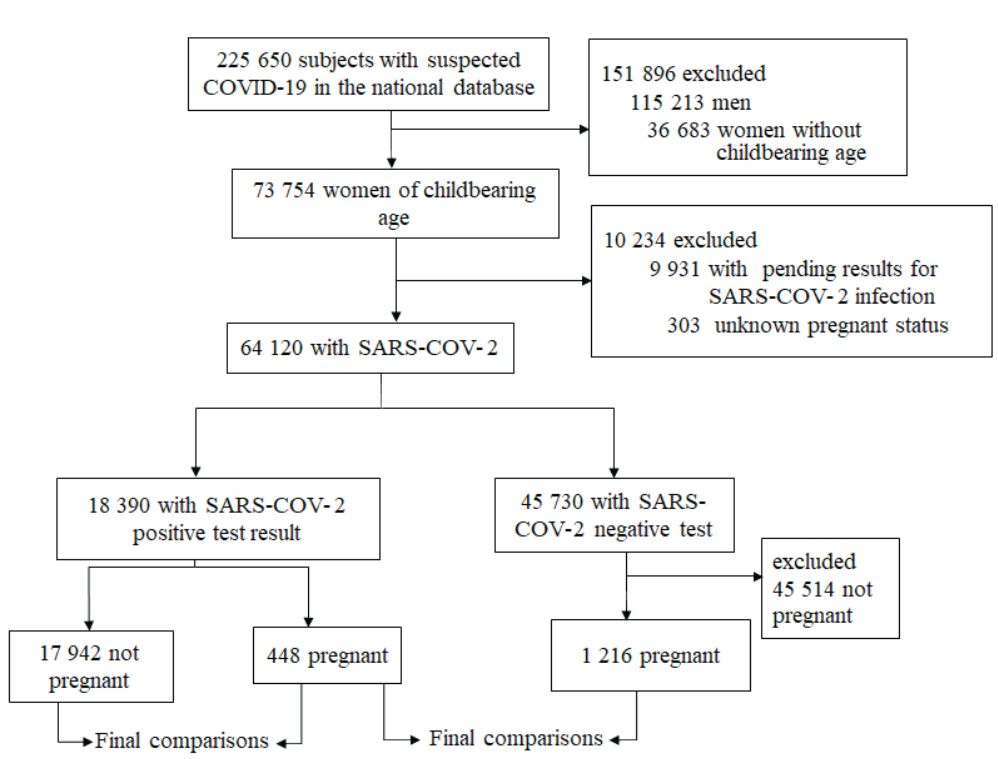

Figure 1. Flowchart of the study.

Table 2. Clinical characteristics of pregnant women according to type of patient care

\begin{tabular}{|c|c|c|c|}
\hline & $\begin{array}{l}\text { No. HOSPITAUIZED (\%) } \\
(\mathrm{N}=137)\end{array}$ & $\begin{array}{l}\text { No. amBulatory (\%) } \\
(\mathrm{N}=\mathbf{3 1 1})\end{array}$ & Pvalue* \\
\hline Age, years (median, IQR) & $29(23.5-32.5)$ & $29(22-33)$ & 0.6 \\
\hline $\mathrm{DM}$ & $11(8 \%)$ & $6(1.9 \%)$ & 0.002 \\
\hline COPD & $0(0 \%)$ & $1(0.3 \%)$ & 0.5 \\
\hline Asthma & $3(2.2 \%)$ & $8(2.6 \%)$ & 0.8 \\
\hline Immunosuppression & $3(2.2 \%)$ & $4(1.3 \%)$ & 0.4 \\
\hline Hypertension & $5(3.6 \%)$ & $12(3.9 \%)$ & 0.9 \\
\hline Obesity & $22(16.1 \%)$ & $37(11.9 \%)$ & 0.3 \\
\hline Cardiovascular disease & $0(0 \%)$ & $2(0.6 \%)$ & 0.4 \\
\hline Chronic kidney disease & $0(0 \%)$ & $2(0.6 \%)$ & 0.3 \\
\hline Smoking & $3(2.2 \%)$ & $9(2.9 \%)$ & 0.6 \\
\hline Other comorbidity & $13(9.5 \%)$ & $19(6.1 \%)$ & 0.2 \\
\hline
\end{tabular}

DM - diabetes mellitus, COPD - chronic obstructive pulmonary disease, IQR - interquartile range.

*Mann-Whitney U test for continuous variables, $\chi 22$ for categorical variables.
However, no significant differences in age were found between outpatients and hospitalized patients in the pregnant group. On the other hand, pregnant patients had a higher risk of being hospitalized ( $R R=2.10,95 \% \mathrm{CI}=1.82-2.55)$. However, significant differences in the frequency of comorbidities were not found between ambulatory and hospitalized patients (Table 2).

Ten $(2.2 \%)$ of the pregnant women died. In both pregnant and non-pregnant patients, age was significantly higher among patients who died; the median age of pregnant patients who died was 34.5 years $(I Q R=25.5-39)$ vs 29 years (IQR $=25-32 ; P<0.001)$. Nine of the pregnant patients who died had pneumonia, nine were hospitalized, three were in the ICU, and two were managed with mechanical ventilatory assistance; they did not have a higher risk of complications (admission to the ICU, pneumonia, or requirement for mechanical ventilation) or death than the controls in both the bivariate analysis ( $R R=0.82,95 \% \mathrm{CI}=0.44-1.53)$ ( Table 3 ) and the survival analysis (hazard ratio $(\mathrm{HR})=0.74,95 \% \mathrm{CI}=0.35-1.56)($ Figure 2$)$.

In the multivariate analysis, each comorbidity was entered into the model with age and pregnancy status, but only the history of DM and chronic kidney disease remained independently associated with death for SARS-CoV-2 in the positive cohort (Table 4).

\section{Pregnant women with suspected COVID-19}

We compared pregnant patients with suspected COVID-19 and a positive test vs those with a negative test. Bivariate analysis showed that pregnant patients with a positive test

Table 3. Clinical evolution of suspected COVID-19 in women of childbearing age

\begin{tabular}{|c|c|c|c|c|c|}
\hline & $\begin{array}{l}\text { No. PregNANT POSITIVE TEST (\%) } \\
(\mathrm{N}=448)\end{array}$ & $\begin{array}{l}\text { No. Not PREgNANT ( } \%) \\
(\mathrm{N}=17942)\end{array}$ & Pvalue $^{*}$ & $\begin{array}{l}\text { No. pregnant megative test (\%) } \\
((\mathrm{N}=1216)\end{array}$ & P valuet \\
\hline \multicolumn{6}{|l|}{ Type of patient care } \\
\hline Ambulatory & $311(69.4 \%)$ & $14891(83 \%)$ & $<0.001$ & $883(72.6 \%)$ & 0.1 \\
\hline Hospitalized & $137(30.6 \%)$ & $3001(17 \%)$ & & $333(27.1 \%)$ & \\
\hline Pneumonia & $62(13.8 \%)$ & $1834(13.4 \%)$ & 0.7 & $74(6.0 \%)$ & $<0.001$ \\
\hline Required mechanic ventilation & $7(5.1 \%)$ & $174(5.7 \%)$ & 0.7 & $6(1.8 \%)$ & 0.04 \\
\hline Admitted to ICU & $14(10.2 \%)$ & $227(7.4 \%)$ & 0.2 & $20(6.0 \%)$ & 0.1 \\
\hline Died & $10(2.2 \%)$ & $484(2.7 \%)$ & 0.5 & $7(0.6 \%)$ & 0.003 \\
\hline \multicolumn{6}{|l|}{ Days from: } \\
\hline Symptoms to admission (median, IQR) & $3(2-5)$ & $4(2-6)$ & 0.7 & $2(1-4)$ & $<0.001$ \\
\hline Admission to death (median, IQR) & $7.5(2.75-9.75)$ & $5(2-9)$ & 0.5 & $1(0-2)$ & 0.07 \\
\hline Symptoms to death (median, IQR) & $10(4.75-11.75)$ & $9(6-14)$ & 0.9 & $4(2-6)$ & 0.03 \\
\hline
\end{tabular}

ICU - Intensive care unit, IQR - interquartile range

*Mann-Whitney U test for continuous variables, $\chi 2$ test for categorical variables comparing pregnant with positive test vs not pregnant with positive test.

$†$ Mann-Whitney U test for continuous variables, $\chi 2$ test for categorical variables comparing pregnant with positive test vs pregnant with negative test. 


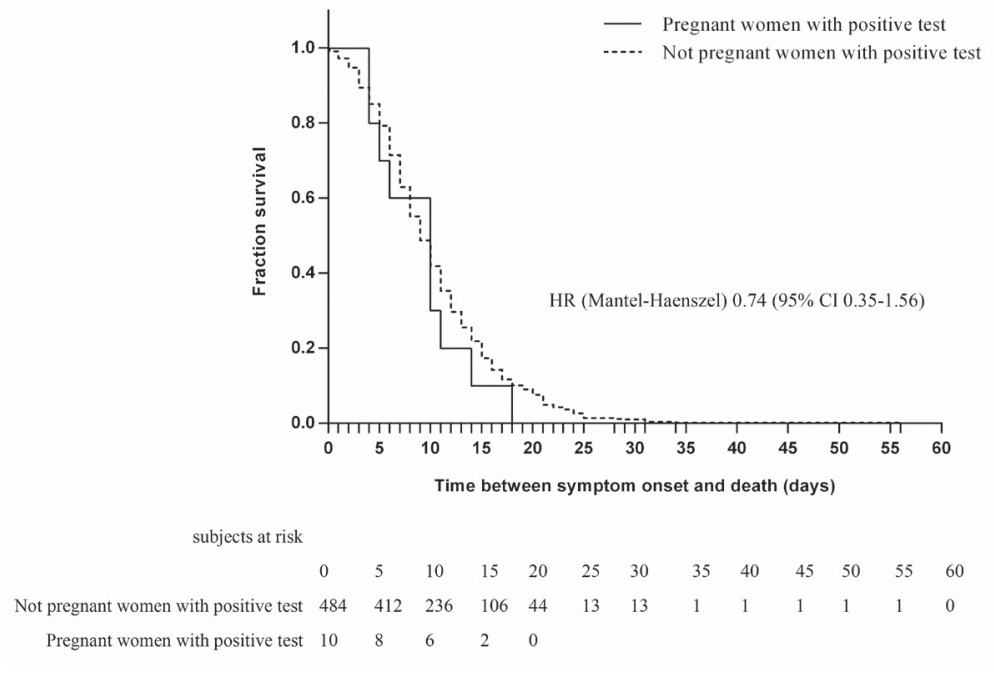

Figure 2. Kaplan-Meier cumulative estimates of propability of death in positive pregnant group compared with positive not pregnant group. were older than patients with a negative test, and they had a higher frequency of obesity (Table 1).

Regarding clinical evolution, we did not find differences in the type of medical care received by patients with or without a positive test. Seven (0.6\%) pregnant women with a negative test died; these patients had fewer days from the beginning of symptoms until admission or death and from admission to death with respect to pregnant women with a positive test (Table 3). Three of these patients were diagnosed with pneumonia, two were admitted to the ICU, and one required mechanical ventilation. In bivariate analysis, patients with a positive test had a higher risk of death than patients with a negative test ( $\mathrm{RR}=3.87,95 \% \mathrm{CI}=1.48-10.12$ ), but we found no significant difference in 60-day mortali-

Table 4. Bivariable and multivariable analysis of potential prognostic variables associated with 60-d COVID-19 mortality in women of childbearing age

\begin{tabular}{|c|c|c|}
\hline & UnIVARIABIF (RR, 95\%) & Mutivariabie (HR, 95\% CI)* \\
\hline \multicolumn{3}{|c|}{ DM: } \\
\hline no & 1 (ref) & 1 (ref) \\
\hline yes & $5.09(4.47-5.78)$ & $1.23(1.02-1.49)$ \\
\hline \multicolumn{3}{|c|}{ COPD: } \\
\hline no & 1 (ref) & 1 (ref) \\
\hline yes & $6.41(3.49-11.77)$ & $1.33(0.75-2.36)$ \\
\hline \multicolumn{3}{|c|}{ Asthma: } \\
\hline no & 1 (ref) & 1 (ref) \\
\hline yes & $1.08(0.72-1.62)$ & $0.79(0.51-1.26)$ \\
\hline \multicolumn{3}{|c|}{ Immunosuppression: } \\
\hline no & 1 (ref) & 1 (ref) \\
\hline yes & $3.95(2.59-6.01)$ & $1.48(0.97-2.26)$ \\
\hline \multicolumn{3}{|c|}{ Hypertension: } \\
\hline no & 1 (ref) & 1 (ref) \\
\hline yes & $3.66(3.19-4.22)$ & $1.05(0.94-1.40)$ \\
\hline \multicolumn{3}{|c|}{ Obesity: } \\
\hline no & 1 (ref) & 1 (ref) \\
\hline yes & $1.79(1.58-2.03)$ & $1.01(0.84-1.22)$ \\
\hline
\end{tabular}

\section{UnIVABiabie (RR, 95\%) Multivariabie (HR, 95\% CI)*} Chronic kidney disease

\begin{tabular}{|c|c|c|}
\hline no & 1 (ref) & 1 (ref) \\
\hline yes & $9.44(6.80-13.01)$ & $1.72(1.25-2.38)$ \\
\hline \multicolumn{3}{|c|}{ Cardiovascular disease: } \\
\hline no & 1 (ref) & 1 (ref) \\
\hline yes & $2.31(1.30-4.12)$ & $0.84(0.34-2.03)$ \\
\hline \multicolumn{3}{|c|}{ Smoking: } \\
\hline no & 1 (ref) & 1 (ref) \\
\hline yes & $0.81(0.542-1.21)$ & $1.14(0.75-1.73)$ \\
\hline \multicolumn{3}{|c|}{ Other comorbidity: } \\
\hline no & 1 (ref) & 1 (ref) \\
\hline yes & $1.83(1.31-2.57)$ & $0.85(0.58-1.25)$ \\
\hline
\end{tabular}

RR - relative risk, HR - hazard ration, DM - diabetes mellitus, COPD chronic obstructive pulmonary disease

*Corrected for age and pregnancy status.

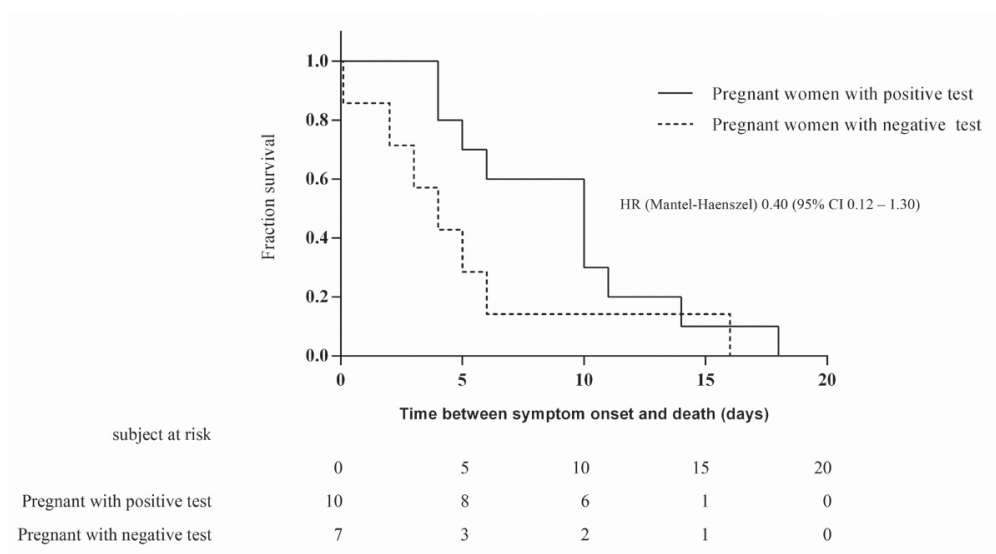

Figure 3. Kaplan-Meier cumulative estimates of propability of death in positive pregnant group compared with negative pregnant group. ty $(\mathrm{HR}=0.40,95 \% \mathrm{CI}=0.12-1.30)$ (Figure 3). In the multivariate analysis, obesity remained a risk factor for the risk of a positive test in pregnant patients (Table 5).

\section{DISCUSSION}

The analysis presented here represents the largest cohort of pregnant women laboratory-tested for COVID-19 from a single country. In our results, we found a lethality of $2.2 \%$ among pregnant women. We also found that pregnant women positive for COVID-19 did not have an increased risk of mortality or complications with respect to a control group of women of childbearing age who were not pregnant but 
Table 5. Bivariable and multivariable analysis of potential prognostic variables associated with a SARS-COV-2 positive test in pregnant women with suspected COVID-19

\begin{tabular}{|c|c|c|}
\hline & $\begin{array}{l}\text { Unwiakiabif } \\
(\mathrm{RR}, 95 \%)\end{array}$ & $\begin{array}{l}\text { MuLtivaRIABIE } \\
\text { (HR, 95\% CI)* }\end{array}$ \\
\hline \multicolumn{3}{|c|}{ DM: } \\
\hline no & 1 (ref) & 1 (ref) \\
\hline yes & $0.59(0.88-2.86)$ & $1.07(0.64-1.78)$ \\
\hline \multicolumn{3}{|c|}{ COPD: } \\
\hline no & 1 (ref) & 1 (ref) \\
\hline yes & $0.90(0.09-8.66)$ & $1.37(0.17-10.93)$ \\
\hline \multicolumn{3}{|c|}{ Asthma: } \\
\hline no & 1 (ref) & 1 (ref) \\
\hline yes & $0.50(0.26-0.95)$ & $0.46(0.25-0.86)$ \\
\hline \multicolumn{3}{|c|}{ Immunosuppression: } \\
\hline no & 1 (ref) & 1 (ref) \\
\hline yes & $0.79(0.34-1.82)$ & $1.20(0.55-2.60)$ \\
\hline
\end{tabular}

\begin{tabular}{|c|c|c|}
\hline \multicolumn{3}{|c|}{ Hypertension: } \\
\hline no & 1 (ref) & 1 (ref) \\
\hline yes & $1.2(0.69-2.12)$ & $1.41(0.85-2.36)$ \\
\hline \multicolumn{3}{|c|}{ Obesity: } \\
\hline no & 1 (ref) & 1 (ref) \\
\hline yes & $1.56(1.16-2.12)$ & $1.36(1.02-1.81)$ \\
\hline \multicolumn{3}{|c|}{ Chronic kidney disease: } \\
\hline no & 1 (ref) & 1 (ref) \\
\hline yes & $1.08(0.21-5.57)$ & $2.01(0.40-8.49)$ \\
\hline \multicolumn{3}{|c|}{ Cardiovascular disease: } \\
\hline no & 1 (ref) & 1 (ref) \\
\hline yes & $0.67(0.14-3.18)$ & $0.59(0.66-1.37)$ \\
\hline \multicolumn{3}{|c|}{ Smoking: } \\
\hline no & 1 (ref) & 1 (ref) \\
\hline yes & $0.85(0.45-1.62)$ & $0.78(0.44-1.40)$ \\
\hline \multicolumn{3}{|c|}{ Another comorbidity: } \\
\hline no & 1 (ref) & 1 (ref) \\
\hline yes & $1.01(0.68-1.49)$ & $0.95(0.66-1.37)$ \\
\hline
\end{tabular}

$\mathrm{RR}$ - relative risk, HR - hazard ratio, DM - diabetes mellitus, COPD - chronic obstructive pulmonary disease

*Corrected for all variables and age. positive for COVID-19. Similarly, pregnant women with confirmed COVID-19 had no higher risk of death than pregnant women with a negative test.

Most previous publications have been case series with a very low number of patients [13], and some systematic reviews were carried out analyzing these case series. A systematic review of 108 pregnant patients included mostly women from China, with some cases from Sweden, the USA, Korea, and Honduras, with ages similar to our cohort. In this review, 3\% of patients were admitted to the ICU and no deaths were reported [14]. In another systematic review, Elshafeey et al. [15] analyzed 33 studies including 385 pregnant women; they reported one maternal death and lower frequencies of admission to the ICU or requirement for mechanical ventilation than our cohort. However, they did not make a comparison with a control group and the risk of complications could not be estimated. Another case series [16] compared the evolution of pregnant patients with COVID-19 and their positive contacts; they observed a more torpid evolution in pregnant women than their contacts but could not reach conclusions due to a low case number.

We identified that pregnant patients with a positive test have a higher risk of being hospitalized than non-pregnant patients with a positive test, which could be due to, in addition to the respiratory symptoms associated with COVID-19, they had obstetrics indications for hospitalization as indicated by the Mexican guidelines for the care of pregnancy, childbirth, and the puerperium during the COVID-19 pandemic [17]. Unfortunately, the obstetric characteristics of the patients are not specified in the database.

The presence of chronic degenerative diseases is related to an increased risk of complications and death from COVID-19 [18], including in Mexico [19]. However, as other authors indicated previously [20], the impact of these highly prevalent diseases on the clinical evolution of COVID-19 in pregnant women has

not been analyzed. We found that DM and chronic kidney disease are risk factors for death among patients of childbearing age with a positive test, but were not found as risk factors for mortality among pregnant patients with or without a positive test. However, obesity was a risk factor for a positive test in pregnant women with suspected COVID-19.

Moreover, we identified that the patients with a negative test had a shorter duration from the onset of symptoms until death than pregnant women with positive test, which may be because the causes of death in these patients were not related to respiratory symptoms, which were classified as suspicious. Unfortunately, the causes of the deaths were not registered, yet the pregnant patients with a positive test had a higher risk of death than the patients with a negative test. Therefore, it seems that pregnant patients with a negative test die less frequently but more quickly than pregnant patients with a positive test. In addition, only data from pregnant women suspected of COVID-19 are included in this study, and could not be compared to other causes of mortality in pregnant women with negative tests and without respiratory disease. Because of this, we consider it more appropriate to compare the risk of pregnant patients with a positive test and non-pregnant patients with a positive test, which showed that pregnancy does not increase the risk of death.

This study has several limitations. First, information on the obstetric characteristics of the pregnant patients, such as gestational age, resolution of pregnancy, obstetric diseases and complications, and perinatal history, was missing. In addition, the symptoms presented by the patients were unknown. Other causes of hospitalization, ICU admission, and death could not be analyzed because the database only includes women suspected of having COVID-19. Therefore, the role of COVID-19 in the general mortality of pregnant women was not established. 
On the other hand, this study is a large cohort from a single country to analyze the risk of complications and mortality in pregnant patients with RT-PCR-confirmed COVID-19, and we performed a comparison with two control groups: COVID-19-positive women of childbearing age and pregnant women with respiratory symptoms but a negative test for SARS-CoV-2. We also estimate the association between the presence of complications and death and the history of pre-existing comorbidities, mainly chronic-degenerative diseases. We found that pregnancy is not a risk factor for COVID-19 mortality, but pregnant women had a higher risk of being hospitalized and a higher frequency of ICU admission than non-pregnant women, and they had a lower median age and reduced non-specified comorbidities. In Cox regression analysis, diabetes and chronic kidney disease remain risk factors for mortality in the cohort.

Since the beginning of the pandemic, pregnant patients have been identified as a vulnerable group for complications and risk of death from COVID-19 due to previous experiences, such as pandemic influenza. This is likely why medical staff decide more frequently on the hospitalization when pregnant patients ask for medical attention, and they may be more careful in identifying COVID-19 complications earlier. These results offer solid evidence of SARS-CoV-2 infection, how severe it is, and outcomes in the specific context of pregnancy. We provide evidence supporting specific guidelines for pregnancy care during SARS-COV-2 infection.

\section{CONCLUSIONS}

In Mexico, pregnant patients with laboratory-confirmed COVID-19 do not have a greater risk of complications or death from COVID-19 than non-pregnant patients with laboratory-confirmed COVID-19 or pregnant patients with a negative test. However, the presence of DM and chronic kidney disease increases the risk of death in women of childbearing age, but not particularly in pregnant patients. The causes of death in pregnant patients with symptoms suspicious of COVID-19 but a negative test need to examined more thoroughly, as these patients present with a faster evolution toward death.

Acknowledgments: This study was done without grants. We thank all front-line medical staff and public health workers in the epidemiology surveillance system of General Epidemiology Directorate of the Mexican Health Ministry who collected these important data.

Ethics and consent to participate: This study was carried out with anonymous data obtained from the open national database of COVID-19 from the Ministry of Health of Mexico. The database is available under an international license, CC-BY-ND 4.0.

Data sharing: The database of the epidemiological surveillance system administered by the General Directorate of Epidemiology of the Secretary of Health of Mexico is a database open to the general public, but this is updated every day, and the analyzed data correspond to what was available May 25, 2020, which can be consulted at https:// Figureshare.com/s/bbcca55a83d58dfd9eed.

Funding: All authors are employed and all expenses covered by federal state or publicly university institutions. No specific funding was received for this study.

Author Contributions: MRS, OMC, and MH contributed to the study design, the literature search, and writing the report; MRS, EMZ, and XT contributed with data collection, data analysis, and data interpretation. All authors reviewed and approved the final version of the report.

Competing interests: "The authors completed the ICMJE Unified Competing Interest form (available upon request from the corresponding author), and declare no conflicts of interest.

1 Guan WJ, Liang WH, Zhao Y, Liang H, Chen Z, Li Y, et al. Comorbidity and its impact on 1590 patients with COVID-19 in China: a nationwide analysis. Eur Respir J. 2020;55:2000547. Medline:32217650 doi:10.1183/13993003.00547-2020

2 Buekens P, Alger J, Bréart G, Cafferata ML, Harville E, Tomasso G. A call for action for COVID-19 surveillance and research during pregnancy. Lancet Glob Health. 2020. Medline:32333854 doi:10.1016/S2214-109X(20)30206-0

3 Schwartz DA, Graham AL. Potential Maternal and Infant Outcomes from (Wuhan) Coronavirus 2019-nCoV Infecting Pregnant Women: Lessons from SARS, MERS, and Other Human Coronavirus Infections. Viruses. 2020;12:194. Medline:32050635 doi:10.3390/v12020194

4 Monteleone PA, Nakano M, Lazar V, Gomes AP. de H Martin, Bonetti TC. A review of initial data on pregnancy during th)e COVID-19 outbreak: implications for assisted reproductive treatments. JBRA Assist Reprod. 2020;24:219-25. Medline:32301600 
5 Liang H, Acharya G. Novel corona virus disease (COVID-19) in pregnancy: What clinical recommendations to follow? Acta Obstet Gynecol Scand. 2020;99:439-42. Medline:32141062 doi:10.1111/aogs.13836

6 Rasmussen SA, Smulian JC, Lednicky JA, Wen TS, Jamieson DJ. Coronavirus Disease 2019 (COVID-19) and pregnancy: what obstetricians need to know. Am J Obstet Gynecol. 2020;222:415-26. Medline:32105680 doi:10.1016/j. ajog.2020.02.017

7 Datos en salud. Available: http://sinaiscap.salud.gob.mx:8080/DGIS/. Accessed: 25 May 2020.

8 Hernández-Higareda S, Pérez-Pérez OA, Balderas-Peña LM, Martínez-Herrera BE, Salcedo-Rocha AL, Ramírez-Conchas RE. Maternal metabolic diseases related to pre-pregnancy overweight and obesity in mexican women with high risk pregnancy. Cir Cir. 2017;85:292-8. Medline:27955851 doi:10.1016/j.circen.2017.08.003

9 Kuri-Morales P, Guevara-Guzmán R, Phillips-Gutiérrez V, Mota-Sánchez A, Díaz-Olavarrieta C. National panorama of adolescent pregnancy in Mexico: lessons learned in a six-year period. Gac Med Mex. 2020;156:150-5. Medline:32285856 doi:10.24875/GMM.M20000357

10 Roberton T, Carter ED, Chou VB, Stegmuller AR, Jackson BD, Tam Y, et al. Early estimates of the indirect effects of the COVID-19 pandemic on maternal and child mortality in low-income and middle-income countries: a modelling study. Lancet Glob Health. 2020;8:e901-e908. Medline:32405459 doi:10.1016/S2214-109X(20)30229-1

11 World Health Organization. Reproductive Health Indicators Reproductive Health and Research Guidelines for their generation, interpretation and analysis for global monitoring. Geneva: WHO; 2006.

12 Ministry of Health of Mexico. Información referente a casos COVID-19 en México. Available: https://datos.gob.mx/busca/dataset. Accessed: 25 May 2020.

13 Gonçalves AK. The Real Impact of the Coronavirus Disease 2019 (covid-19) on the Pregnancy Outcome. O impacto real da doença do coronavirus 2019 (covid-19) no desfecho da gestação. Rev Bras Ginecol Obstet. 2020;42:303-4. Medline:32483811

14 Zaigham M, Andersson O. Maternal and Perinatal Outcomes With COVID-19: A Systematic Review of 108 Pregnancies. Acta Obstet Gynecol Scand. 2020;99:823-9. Medline:32259279 doi:10.1111/aogs. 13867

15 Elshafeey F, Magdi R, Hindi N, Elshebiny M, Farrag N, Mahdy S, et al. A systematic scoping review of COVID-19 during pregnancy and childbirth. Int J Gynaecol Obstet. 2020;150:47-52. Medline:32330287 doi:10.1002/ijgo.13182

16 Hantoushzadeh S, Shamshirsaz AA, Aleyasin A, Seferovic MD, Aski SK, Arian SE, et al. Maternal Death Due to COVID-19. Am J Obstet Gynecol. 2020;223: 109.el-109.e16. Medline:32360108 doi:10.1016/j.ajog.2020.04.030

17 Ministry of Health of Mexico. Guidelines for the prevention and mitigation of COVID-19 in the care of pregnancy, childbirth, the puerperium and the newborn. Available: https://www.gob.mx/cms/uploads/attachment/file/546239/Lineamiento_prevencion_y_mitigacion_de_COVID-19_en_el_embarazo_CNEGSR_1_.pdf. Accessed: June 01, 2020.

18 Wang B, Li R, Lu Z, Huang Y. Does comorbidity increase the risk of patients with COVID-19: evidence from meta-analysis. Aging (Albany NY). 2020;12:6049-57. Medline:32267833 doi:10.18632/aging.103000

19 Bello-Chavolla OY, Bahena-López JP, Antonio-Villa NE, Vargas-Vázquez A, González-Díaz A, Márquez-Salinas A,et al. Predicting mortality due to SARS-CoV-2: A mechanistic score relating obesity and diabetes to COVID-19 outcomes in Mexico. J Clin Endocrinol Metab. 2020;dgaa346. Medline:32474598 doi:10.1210/clinem/dgaa346

20 Kapur A, Hod M. Maternal health and non-communicable disease prevention: An investment case for the post COVID-19 world and need for better health economic data. Int J Gynaecol Obstet. 2020. Medline:32401348 doi:10.1002/ijgo.13198 